\title{
Los jóvenes y la
}

democracia: retos

y perspectivas para

el ejercicio de su

ciudadanía* / Youth

and Democracy:

Challenges and

Perspectives for the

Achievement of

their Citizenship

* Recibido: 27 de febrero de 2014. Aceptado: 4 de abril de 2014.

Tla-Melaua, revista de Ciencias Sociales. Facultad de Derecho y Ciencias Sociales.

Benemérita Universidad Autónoma de Puebla, México / IssN: 1870-6916 / Nueva Época,

Año 8, No 37, octubre 2014 / marzo 2015, pp. 30-49. 
El presente artículo aborda la problemática que enfrentan algunos sectores de jóvenes, entre 18 y 29 años, cuyo ejercicio de la ciudadanía se ve obstaculizado cuando pertenecen a los estratos de mayor vulnerabilidad social. Dichos estratos son la baja escolaridad, la paternidad o maternidad temprana, bajos ingresos, origen étnico u orientación sexual. Los altos niveles de discriminación aún imperan en México; esto acarrea consecuencias negativas en los planos económico, político y social: violencia, narcotráfico, migración, baja participación política y abstencionismo electoral, drogadicción o alcoholismo, y en el alto número de jóvenes víctimas del lenocinio.

\section{PALABRAS CLAVE}

Jóvenes, ciudadanía, democracia integral, violencia, vulnerabilidad social.
This article addresses the difficulties that different youth sectors between the ages of 18 to 29, whose citizenship practices are hindered simply because they belong to a socially vulnerable strata. Such as: low education level, parenthood or pre-premature maternity, despicable salaries, ethnic origin or sexual orientation. Highest levels of discrimination that are still present in Mexico; this has had negative consequences in economic, political and social levels, violence, drug trafficking, migration, hardly any political participation and voter turnout, drug addiction or alcoholism, and a high level of young victims being pimped.

KEYWORDS

Young people, Citizenship, Integral Democracy, Violence, Social vulnerability.

\footnotetext{
* Profesor investigador en la Facultad de Derecho y Ciencias Sociales de la Benemérita Universidad Autónoma de Puebla (BUAP), México. (oscarantoniogob@hotmail.com)
} 
1. Introducción / 2. El modelo sectorial / 3. Democracia societal y ciudadanía integral / 4. El sector de mayor vulnerabilidad social / 5. Baja escolaridad / 6. Orientación sexual, origen étnico y madres solteras / 7. Efectos económicos, políticos y sociales / 8. Conclusiones

\section{INTRODUCCIÓN}

El objetivo general del presente artículo es describir, analizar y explicar las problemáticas económicas, políticas y sociales que obstaculizan el ejercicio de la ciudadanía en los jóvenes de los sectores más vulnerables de la sociedad mexicana.

Los jóvenes no son un grupo homogéneo. Los “jóvenes”, como concepto, se encuentran en una categoría de análisis de contenido histórico, social, económico y político. Dos de las variables demográficas más importantes de este concepto son la edad y el género. Poseen características, metas, anhelos e interacciones sociales diferentes; dependiendo de estas variables, los jóvenes asumen distintas maneras de percibir el mundo y de actuar sobre él.

Empero, además de todos estos criterios sociológicos, hemos de considerar la trayectoria que los lleva al ejercicio de su ciudadanía en un sentido amplio. Muchas de las veces, los sectores juveniles de mayor vulnerabilidad social no encuentran un camino hacia el correcto ejercicio de su ciudadanía.

Este es el asunto que interesa tratar; para ello, formulo las siguientes preguntas: ¿Qué atributos contiene el sector de las culturas juveniles más vulnerable en términos sociales? ¿Cuáles son las repercusiones económicas, políticas y sociales de estar en ese sector de alta vulnerabilidad social? ¿En qué medida se ven afectadas las posibilidades de ejercer una ciudadanía integral? 
Para contestar a estas preguntas, he distribuido el desarrollo del trabajo en tres apartados. El primero de ellos, intitulado "El modelo sectorial", consistirá en la descripción del sector de jóvenes que interesa abordar; me ayudaré de un esquema, construido a manera de intersecciones de subconjuntos, ${ }^{1}$ que pueda describir sus propiedades, atributos y características.

En el segundo, hablaré propiamente de la democracia societal y de la ciudadanía integral como uno de los grandes objetivos e ideales que cualquier sociedad que se denomine o se haga llamar democrática pretenda aspirar. Este ejercicio nos ubicaría en el análisis, y mostraría cuán lejos estamos los mexicanos, sobre todo los jóvenes de nuestro país (y más aún, el sector o sectores más vulnerables), de alcanzar una ciudadanía plena.

El tercer apartado estará constituido por la exposición del modelo. Discutiremos sobre los atributos del sector y los efectos sociales, económicos y políticos que aquéllos pueden provocar: migración, violencia, baja o nula participación política y el abstencionismo electoral, drogadicción, alcoholismo y lenocinio.

Es de obligada mención que, a partir de la puesta en marcha de la denominada "guerra contra el narcotráfico" (después llamada "lucha contra la delincuencia"), emprendida por el entonces titular del Ejecutivo, Felipe Calderón, el país se ha sumido en una espiral de violencia sin precedentes, en la cual los jóvenes están directamente involucrados: como perpetradores y como víctimas de todas las calamidades, inducidos por las cabezas de los distintos cárteles del narcotráfico, así como de diversas organizaciones delincuenciales en el país.

Esta situación ha potenciado al máximo la ya de por sí lamentable situación de los grupos vulnerables de jóvenes, cuyos cuerpos, desgraciadamente, en la mayoría de los casos, acaban en fosas clandestinas.

\footnotetext{
${ }^{1}$ Este modelo está construido a partir de reglas muy sencillas diseñadas a partir de la teoría de conjuntos dentro de la ciencia formal de la matemática. A partir de un conjunto universo, se encontrarían diversos subconjuntos que forman parte de él. Sin embargo, cuando éstos o parte de ellos se encuentran "traslapados" entre sí, se forman las intersecciones. Una intersección contiene los atributos o propiedades de los subconjuntos que se encuentran traslapados o interseccionados.
} 
Esquema 1. Modelo sectorial: Jóvenes entre 18 y 29 años con escolaridad e ingresos bajos y con paternidad o maternidad tempranas.

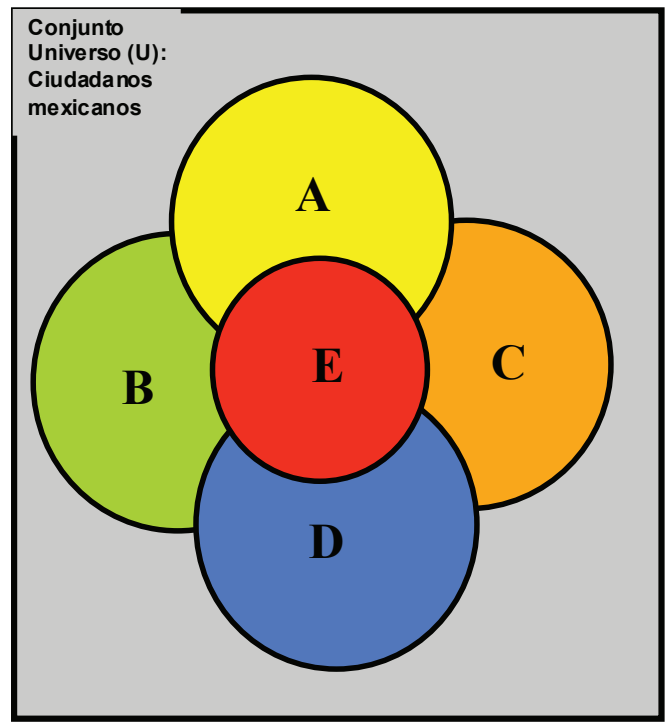

Efectos:

Migración

Violencia

Baja participación política

\section{Abstencionismo electoral}

\section{Drogadicción y} alcoholismo

\section{Narcotráfico}

\section{Lenocinio}

\section{Bajos ingresos}

Intersección:

Baja escolaridad

A, B, C, D

\section{EL MODELO SECTORIAL}

Como he expuesto en la introducción de este artículo, el modelo del sector de jóvenes fue construido a manera de intersección de subconjuntos de la población mexicana (véase esquema 1). El conjunto universo es el total de la población mexicana.

El subconjunto (A) estaría conformado por jóvenes dentro del rango de 18 a 29 años. Los límites tanto inferior como superior están pensados 
arbitrariamente, puesto que las personas de 14 o 15 años en adelante podrían considerarse como jóvenes; sin embargo, decidí comenzar en la edad de 18 años, toda vez que es la edad en la que la Constitución Política de los Estados Unidos Mexicanos determina que un connacional puede ejercer uno de sus derechos cívicos y políticos: el voto.

Ahora bien, el subconjunto (B) estaría conformado por los mexicanos de baja escolaridad ${ }^{2}$ cuya intersección con el subconjunto (A) daría como resultado a los jóvenes dentro del rango de 18 a 29 años que registran baja escolaridad.

El subconjunto $(\mathrm{C})$, por su parte, estaría conformado por los mexicanos que presentan paternidad o maternidad tempranas, cuya intersección con los anteriores subconjuntos daría como resultado a los jóvenes entre 18 y 29 años con baja escolaridad y que además tienen hijos; la situación se complica aún más cuando al atributo "madres" se le agrega el de "solteras".

El siguiente subconjunto, (D), estaría conformado por los mexicanos de

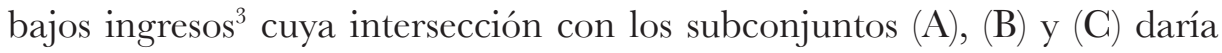
como resultado el subconjunto focal, es decir, la intersección (E), la cual estaría conformada por los mexicanos dentro del rango entre 18 y 29 años con escolaridad e ingresos bajos y con paternidad o maternidad tempranas; dicha intersección conformaría el sector de los jóvenes de mayor vulnerabilidad social. ${ }^{4}$

Ahora bien, ya que he descrito en forma sucinta el modelo en cuestión, expondré la cuestión sobre democracia societal y ciudadanía integral, la cual es una de las grandes carencias de la sociedad mexicana.

\section{DEMOCRACIA SOCIETAL Y CIUDADANÍA INTEGRAL}

La democracia societal ${ }^{5}$ no se limita a las consideraciones electorales o procedimentales o a los aspectos referentes a un concepto de democracia meramente formal; además, toma en cuenta aspectos económicos, sociales, políticos no electorales, y culturales, que enriquecen el concepto. Se erige como un ideal que cualquier sociedad "democrática” debiera pretender alcanzar.

\footnotetext{
${ }^{2}$ Por baja escolaridad entiendo a aquellos jóvenes que aún teniendo secundaria, se pueden considerar como rezagados en comparación con el resto de la sociedad: aquellos mexicanos que no tienen primaria terminada o que sólo tienen primaria, o que tienen estudios de secundaria incompletos.

${ }^{3}$ Entiendo por "mexicanos de bajos ingresos" a aquellos connacionales cuyo nivel de ingreso no alcanza para cubrir las necesidades materiales mínimas que necesitan para vivir.

${ }^{4} \mathrm{El}$ asunto de la vulnerabilidad social será discutido en apartados posteriores; además, analizaremos al objeto de estudio, si añadiéramos tres atributos más: origen étnico, orientación sexual y (en el caso de la maternidad temprana) estado civil.

${ }^{5} \mathrm{El}$ adjetivo societal se ha utilizado por diversos científicos sociales para referirse a un plano más general en donde no sólo se inscribe la esfera social sino también la económica y la política.
} 
La democracia, más allá de un régimen o forma de gobierno, es una forma de vida en donde se ponen de relieve los valores más altos en el sentido humano.

Así, la democracia, en su concepción extensa (societal o integral), no minimalista, tiene que ver con la defensa del Estado de derecho, la división efectiva de poderes, el voto universal, la celebración de comicios periódicos, la competencia efectiva entre partidos políticos; con la defensa institucional de los derechos humanos; con la libertad de expresión, opinión, pensamiento, conciencia, religión, asociación y reuniones pacíficas; con el derecho a la libertad de investigar y de recibir y difundir informaciones e ideas por cualquier medio de expresión.

Tiene que ver también con la participación política (no sólo electoral) activa de la ciudadanía y con la transparencia de la gestión pública; además, este ideal democrático tiene que ver con el respeto a las diferencias étnicas, religiosas, de género, de orientación sexual e ideológicas; sin pasar por alto que la democracia, en total sentido, tiene que ver con el acceso a niveles mínimos de bienestar socioeconómico, pues los valores de igualdad, libertad y justicia no se remiten sólo al ámbito político.

La democracia implica, establece George Sabine, una concepción del ser humano y de la construcción de la ciudadanía integral. En este tenor, el gran ideal de una sociedad que se precie de tener un régimen democrático y que desee democracia en todos los ámbitos, deberá aspirar a ese gran ideal denominado democracia societal: deberá aspirar a alcanzar la ciudadanía integral en donde se integran la civil, la política, y la social (esta última con un factor económico muy importante). La ciudadanía es la condición de pertenencia y participación en la politeia u organización política, donde se integran los miembros de la sociedad. ${ }^{6}$

Más allá de su plasmación en el derecho positivo de las modernas democracias, la ciudadanía hace referencia a un conjunto de prácticas y usos que otorga la cualidad de componentes activos a los individuos en su comunidad de referencia. En este sentido, la ciudadanía es, principalmente, un estatus conformado por el acceso a los recursos básicos para el ejercicio de los derechos y deberes. La no discriminación ${ }^{7}$ en el acceso a esos recursos constituye una de las condiciones necesarias de la ciudadanía.

\footnotetext{
${ }^{6}$ Tal concepto hunde sus raíces etimológicas en la antigua polis griega. En la historia social subsiguiente y, con carácter general, se ha identificado a la politeia con el conjunto de instituciones políticas de la sociedad; su uso no debe hacerse necesariamente sinónimo de Estado en su sentido moderno, el cual corresponde a una fase relativamente reciente del devenir de la humanidad. SABIne, George, Historia de la teoría política, Madrid, España, FCE, 1945.

${ }^{7}$ Entendemos por discriminación, la situación en la cual, por prejuicios, se le da un trato desfavorable a una persona o grupo de personas, generalmente por pertenecer a una categoría social específica.
} 
Caso contrario, los titulares de los derechos permanecerían en una situación de precariedad, expresada como déficit de la ciudadanía. Un hito en la articulación del moderno concepto de ciudadanía, que atañe a su dimensión social, es el del pensador británico Thomas Henry Marshall, emitido en 1949. Marshall tenía la preocupación por teorizar la evolución de la ciudadanía en las sociedades capitalistas como una marcha hacia la igualdad social; distinguía tres ciclos históricos con sus correspondientes factores constitutivos: ${ }^{8}$

- Un factor civil integrado por las capacidades de ejercicio de las libertades individuales fundamentales relativas a la vida y al desarrollo integral de las personas, de expresión y pensamiento, y a las más tangibles de propiedad, contractuales y de sometimiento a los tribunales de justicia;

- Un factor político compuesto por los recursos de participación democrática que competen a las franquicias de elección y mecanismos de representación en la legitimación de la autoridad y el poder político. Por consiguiente, los individuos adquieren su estatus político ciudadano como electores y elegidos;

- Un factor social garantizador de las aspiraciones a una vida digna y al bienestar social de los individuos, con acceso al trabajo remunerado y a la previsión social en situaciones de riesgo; tal estadio correspondería a la consecución de unos estándares de vida básicos legitimados por el conjunto de la ciudadanía.

José Antonio Ocampo ${ }^{9}$ entiende por ciudadanía social la extensión efectiva de los derechos humanos, en su doble dimensión de derechos civiles y políticos, que garantiza la autonomía individual frente al poder del Estado y la participación en las decisiones públicas, y de los derechos económicos, sociales y culturales que responden a valores de igualdad, solidaridad y no discriminación. La ciudadanía social se refiere a aquellos aspectos de la vida de los ciudadanos que afectan el potencial para desarrollar sus capacidades básicas.

Los derechos a la salud y a la educación son considerados componentes básicos de la ciudadanía social. A su vez, la falta de empleo, la pobreza y la desigualdad han sido ampliamente reconocidas como aspectos que obstaculizan la integración de los individuos en la sociedad. En condiciones de extrema pobreza y desigualdad, se dificulta la efectividad de un presupuesto

\footnotetext{
${ }^{8}$ Marshall, Thomas, Ciudadanía y clase social, Madrid, España, Alianza, 1998.

${ }^{9}$ Ocampo, José Antonio, "Economía y democracia “, en La democracia en América Latina, hacia una democracia de ciudadanas y ciudadanos, Buenos Aires, Argentina, Programa de las Naciones Unidas para el Desarrollo (PNUD), 2004.
} 
clave ideal de la democracia: que los individuos son ciudadanos plenos que actúan en una esfera pública donde se relacionan en condiciones iguales. En la medida que la ciudadanía social contiene un componente económico, el empleo ${ }^{10}$ constituye para la mayoría de la población un pilar básico de su ciudadanía.

El trabajo es la forma en que los ciudadanos aportan a la producción de la sociedad y por la cual se hacen de medios que les permiten gozar de sus derechos. $^{11}$

Si bien los derechos civiles y políticos, así como los derechos económicos, sociales y culturales se rigen por estatutos jurídicos diversos en cuanto a su carácter, exigibilidad y mecanismos de protección, todos forman parte de los derechos fundamentales de las personas, reconocidos en las declaraciones y convenciones internacionales correspondientes.

De esta manera, si no se logran avances respecto a los derechos económicos, sociales y culturales, los derechos cívicos y políticos (tan difícilmente alcanzados en México y en muchos países latinoamericanos), tienden a perder sentido para los sectores con menores recursos. Esto es de suma importancia para entender la relación entre democracia societal, ciudadanía social y el asunto que estamos analizando como punto focal de este artículo.

Esquema 2. Ciudadanía integral y sus dimensiones

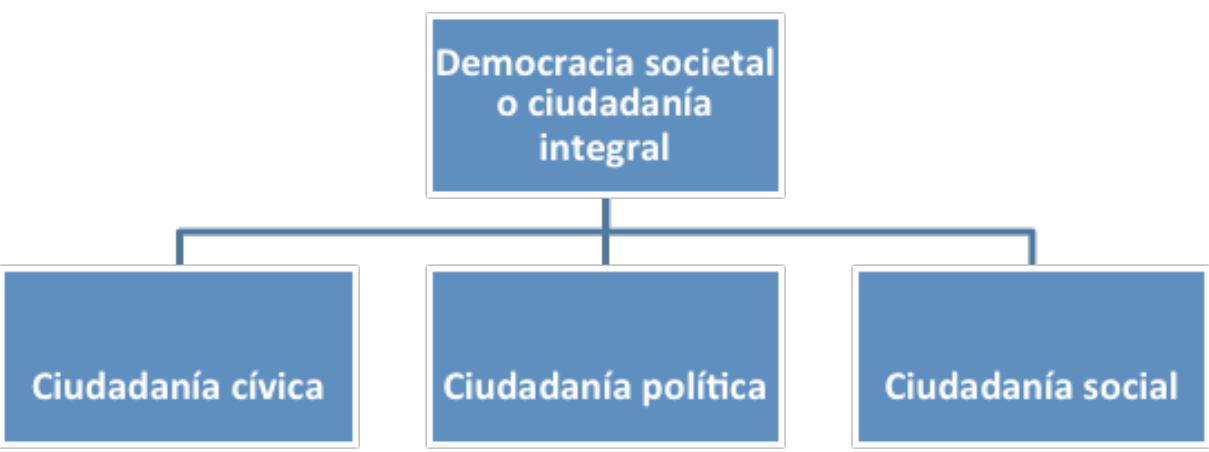

Fuente: Elaboración propia.

\footnotetext{
${ }^{10} \mathrm{El}$ empleo debe estar bien remunerado y cubrir las necesidades básicas. En México y en muchos otros países, existe un gran sector de la población cuyo salario no cumple este requisito. Basta analizar los efectos negativos que, en la economía de muchos sectores de la sociedad mexicana, causaría la posible aplicación del impuesto al valor agregado (IVA) a alimentos y medicinas que ciertos grupos legislativos pretenden aprobar muy probablemente en los primeros meses de 2013.

${ }^{11}$ La situación del empleo ha desmejorado y los niveles de desigualdad se han incrementado considerablemente durante el sexenio de Felipe Calderón.
} 
Existe una relación bidireccional entre ciudadanía integral y desarrollo humano, ${ }^{12}$ puesto que el reforzamiento de la primera implica elevar el segundo, y el reforzamiento de éste último blinda a la ciudadanía integral, sin antes pasar por la social, y ésta es la que, en última instancia, refuerza tanto la política como la civil.

A final de cuentas, la ciudadanía es una figura jurídica montada sobre el reconocimiento de individuos libres, iguales y autónomos, poseedores de derechos y obligaciones para con el Estado y sus instituciones, cuyas reglas deben imperar de manera justa e imparcial, garantizando el pleno desarrollo de aquéllos. Consustancial a la ciudadanía es la existencia de un Estado que asegure libertades básicas de acción política, tránsito, trabajo, así como derechos fundamentales que procuren el desarrollo individual y colectivo, como educación, vivienda, salud.

He descrito cómo sería una situación ideal en torno a la democracia y la ciudadanía integrales; ahora iré a un asunto mucho más concreto, en donde se inscribe la población objeto de estudio, cuyos atributos, anteriormente descritos, conllevan a problemáticas políticas, sociales y económicas.

\section{EL SECTOR DE MAYOR VULNERABILIDAD SOCIAL}

El sector juvenil de mayor vulnerabilidad social es el que tiene baja escolaridad, bajos ingresos, y paternidad o maternidad temprana. Estos atributos lo colocan en desventaja con respecto a otros sectores juveniles. Dicha vulnerabilidad se tornaría todavía más compleja al añadir al atributo de "maternidad temprana", el de "soltera", o bien, a toda esta intersección, añadir el de "indígena" o el tener y manifestar una orientación sexual diferente a la heterosexual, dado el nivel de discriminación que impera en nuestro país.

Los jóvenes de México, como he dicho, no son un grupo homogéneo. $\mathrm{Al}$ igual que en el resto de la población, existen grupos con mayores y menores oportunidades de ejercer sus derechos. Este fenómeno es particularmente relevante en el ejercicio de los derechos sociales, pero también se expresa en los derechos civiles y políticos. García Moreno ${ }^{13}$ establece que el acceso de los adolescentes a una mejor educación redundaría en mejores empleos e incidiría positivamente en la ampliación de sus oportunidades de participación política.

Sin embargo, se observa que esto cada vez se torna más dificil, puesto que en un país como México, donde la gran mayoría de los puestos de

\footnotetext{
${ }^{12}$ El objetivo básico del desarrollo humano es ampliar las oportunidades abiertas a los ciudadanos para vivir una vida saludable con educación y vivienda dignas, creativa y con los medios adecuados para participar en su entorno social.

${ }^{13}$ García Moreno, Mauricio, Ciudadanía, participación, y derechos civiles y políticos de los jóvenes y adolescentes en Ibero América, UnICEF, 2005.
} 
trabajo no requieren alta especialización o un nivel de estudios, el sector de jóvenes o adultos jóvenes con un alto grado de estudios no encuentra empleo en el campo laboral. Este es uno de los sectores más golpeados por la más reciente crisis económica, desatada en 2008 ante la quiebra del banco norteamericano Lehman Brotheres.

García Moreno también establece que un amplio sector de adolescentes y jóvenes se encuentra inserto en un círculo vicioso: mala calidad de la educación y baja escolaridad, trabajo prematuro e ingresos precarios, empleos mal remunerados, escasa educación en valores ciudadanos y baja participación política.

Los efectos tanto de la ineficiencia como de la inequidad del sistema escolar, que en buena medida son reflejo del sistema social, político y principalmente económico (modelo neoliberal monetarista), son catastróficos para el ejercicio de los derechos y para el largo proceso de construcción de una forma de vida democrática. Empuja a los niños al trabajo prematuro y a los adolescentes al trabajo peligroso.

Por otra parte, el embarazo temprano es otro elemento que limita el ejercicio de los derechos; asumir antes de tiempo la responsabilidad de criar a un hijo conlleva grandes obstáculos para la participación política de los jóvenes padres, tanto hombres como mujeres, y para el ejercicio de sus derechos. La mayoría de las veces los obliga a sumirse, en malas condiciones, en la dura tarea de sostener un hogar. ¿Cuántos adolescentes y jóvenes han tenido que abandonar las actividades e inquietudes propias de la gente de su edad? Dichos jóvenes otorgan mayores ganancias a la industria de las fórmulas lácteas, de los pañales desechables, de los biberones, a la de los servicios médicos privados (si no se cuenta con los públicos), entre otras.

En México son muchos, y difícilmente se podría tener un estimado real a pesar de las estadísticas oficiales, toda vez que la realidad es compleja y cambiante y que la situación de polarización económica acentúa la magnitud de dicho sector.

\section{BAJA ESCOLARIDAD}

De acuerdo con el Censo de Población y Vivienda de 2000, más de la mitad de la población de 15 años y más se encontró en condición de rezago educativo, es decir, no contó con la secundaria terminada. ${ }^{14}$ Para el año de 2004, el Instituto Nacional de Estadística, Geografía e Informática (INEGI) calculó que más de 33 millones de hombres y mujeres de 15 años y más no lograron incorporarse o permanecer en el sistema educativo y concluir la educación secundaria.

\footnotetext{
${ }^{14}$ Instituto Nacional de Estadística, Geografía e Informática, XII Censo de Poblacióny Vivienda, 2000.
} 
En 2011, el estudio Mujeres y Hombres en México, del INEGi, estableció que la cobertura en educación media superior se incrementó del año 2000 al año 2010, al pasar de 55 a 67\%; sin embargo, la educación sigue manteniendo serías deficiencias. ${ }^{15}$

Suárez Zozoya ${ }^{16}$ indica que el establecimiento de la educación básica deviene exigencia para la formación de individuos reflexivos, autónomos y racionales, capaces de integrarse a la vida pública como portadores de la representación de su sociedad.

El volumen del rezago educativo es indicador del grado de injusticia que ha existido en el país y del nivel de vulnerabilidad que tienen el mismo y su población ante la actual competencia económica tanto nacional como internacional en condiciones de desventaja.

Ahora bien, uno de los estudios más recientes de la Organización para la Cooperación y Desarrollo Económicos (OCDE) en $2011^{17}$ afirma que existen más de siete millones de jóvenes de entre 15 y 29 años que no estudian ni trabajan. Este no es un dato exacto, pero refleja la realidad de la juventud mexicana. Este sector de la juventud ha sido calificado con el término nini.

México ocupó el tercer lugar entre los países miembro de la organización. Se ubicó en primer lugar en el número de mujeres jóvenes sin empleo ni estudios. El estudio apunta a que México es el país que menos ejerce gasto público en educación como porcentaje del producto interno bruto (PIB $)^{18}$ en comparación con el resto de países miembro.

Para 2012, México ascendió un lugar más en el número de jóvenes ninis, dentro del conjunto de los países de la OCDE: casi 8 millones de jóvenes. ${ }^{19}$ Por lo regular, el fenómeno nini se genera en las clases medias (madias bajas, medias medias y medias altas) además de las clases altas, pues es un extracto de la sociedad que asegura a estos jóvenes la cobertura de sus necesidades básicas: alimentación, techo, vestido y hasta entretenimiento.

Hay diferentes tipos de ninis: los que por falta de una orientación vocacional no se deciden a estudiar alguna carrera universitaria, los egresados universitarios que, al no encontrar empleo en un lapso determinado, se resignan a no estudiar ni trabajar. Además, encontramos los rechazados de alguna institución educativa que, por la decepción, deciden dejar el estudio a un lado. El modelo económico que se cierne sobre México desde 1983,

\footnotetext{
${ }^{15}$ Mujeresy Hombres de México, INEGI, 2011. Disponible en: http://www.inegi.org.mx/prod_serv/contenidos/ espanol/bvinegi/productos/integracion/sociodemografico/mujeresyhombres/2011/MyH2011.pdf.

${ }^{16}$ Suárez Zozoya, María Herlinda, Rezago educativo de los mexicanos en México y en los Estados Unidos, México, Centro Regional de Investigaciones multidisciplinarias de la UnAM, 2009.

${ }^{17}$ Organización para la Cooperación y Desarrollo Económicos (OCDE), Panorama de la educación, 2011.

${ }^{18}$ Recordemos que el PIB es el principal indicador para mediar la actividad económica de un país o conjunto de países. De igual manera, sirve para establecer los rankings económicos por parte del FMI y BM. ${ }^{19}$ Avilés, Karina, "México, segundo lugar de la ocDE en 'ninis' con 7 millones 820 mil", en La fornada, marzo de 2012.
} 
año en el cual se empezaron a aplicar las políticas de ajuste, estabilización y reforma estructural de la economía mexicana (modelo neoliberal monetarista), auspiciadas por el Fondo Monetario Internacional y el Banco Mundial, el proceso de privatización de la educación en detrimento de la pública, aunado al de crisis económica y al propio modelo económico capitalista atrasado y dependiente, han aumentado la cifra de jóvenes en esta situación.

\section{ORIENTACIÓN SEXUAL, ORIGEN ÉTNICO \\ Y MADRES SOLTERAS}

Añadir al sector objeto de estudio los atributos de indígena, ${ }^{20} \mathrm{o}$ una orientación diferente a la heterosexual, implica una situación de mayor vulnerabilidad explicada por la presencia de una discriminación inherente en muchos sectores de la sociedad. ${ }^{21}$ Según estadísticas oficiales ${ }^{22}$ el rezago educativo indígena es de poco más de $86 \%$; si se añade que gran parte de ellos se encuentran subalimentados, analfabetos, enfermos, marginados y pobres, se tiene una bomba de tiempo que ya ha estallado en distintas facetas y momentos.

Muchos de los adolescentes y jóvenes indígenas migran a las ciudades en busca de mejores oportunidades; sin embargo, la discriminación merma sus posibilidades de crecimiento y desarrollo de su ciudadanía y, por supuesto,

\footnotetext{
${ }^{20}$ En una columna de opinión de Ilán Semo, con la cual estoy completamente de acuerdo y asumo la misma postura, afirma que en la revista Lineas de fuga (número 26, pp. 35-49) que dirige Philip Olé, hay un ensayo de Gregorio Regino el cual establece que "la situación de subordinación que comparten todos los pueblos indígenas en el conjunto de la sociedad mexicana ha propiciado que se le asignen características culturales comunes y que el concepto indígena se aplique indiscriminadamente a todos, como si fueran una sola cultura". Establece también que "a finales del siglo XVIII, el protonacionalismo criollo convierte a la geografía social imperial en una perversión nacionalista: reformula el término para mantener a la principal parte de la población (los "indígenas") en una condición de subalternidad". En este sentido, Regino afirma que "el movimiento de Independencia produjo una república que no eliminó el concepto de indígena sino que lo redefinió para fincar un orden estamental: en ese orden la palabra "indígena" homologaba al universo que quedaba fuera del principio de ciudadanía. En rigor el liberalismo mexicano padeció el mismo síndrome que sus homólogos conservadores, para reafirmar una antigua tesis de O’Gorman: el criollismo. Los “indígenas" eran aquellos a los que no se les concedían los atributos suficientes para formar parte legítima del orden público reflexivo, condición central del principio de ciudadanía". El autor indica que "homologar el mosaico cultural y nacional que fue la sociedad mexicana en el siglo xIx bajo un solo concepto permitía al nuevo Estado presentar políticas de desindigenización como cruzadas en nombre de la "civilización”. Regino se pregunta: ¿Qué sentido tiene hoy seguir hablando de "indígenas"? ¿No acaso nos encontramos en un proyecto que aspira a la efectiva ciudadanización de la sociedad? ¿Por qué no hablar de mayas, chontales, mazatecos, popolocas, nahuas, tzotziles... y derogar, erradicar, olvidar esa palabra en la que está inscrita toda la perversión del criollismo? La fornada, febrero de 2009.

${ }^{21}$ Digo inherente puesto que la cultura de la discriminación registrada en muchos de los sectores de la sociedad mexicana se cultiva desde la infancia. ¿Cuántos infantes de jardín de niños o de primaria ya reflejan en su comportamiento la discriminación de sus padres? ¿Cuántos niños ejercen ya la discriminación a sus compañeros por motivos de raza, género, apariencia u otros factores? La sociedad mexicana, como otras, se encuentra enferma.

${ }^{22}$ Consejo Nacional para Prevenir la Discriminación y la Secretaría de Desarrollo Social, Encuesta Nacional sobre Discriminación en México, 2005.
} 
desarrollo humano. En promedio, nueve de cada diez indígenas opina que existe discriminación por su condición, según la primera encuesta nacional sobre discriminación en México llevada a cabo en 2005; ${ }^{23}$ sin embargo, la encuesta de 2012 no varía significativamente en estas percepciones. ${ }^{24}$

Cosa no diferente presentan los homosexuales. ${ }^{25}$ Muchos de ellos son víctimas de la discriminación, lo cual repercute de forma negativa en el ejercicio de sus garantías individuales y derechos civiles. Aunado a ello, se han presentado en México múltiples casos de adolescentes y jóvenes asesinados y torturados por razones de homofobia. ${ }^{26}$ Ésta se explica, en parte (lo formulo como hipótesis), por el proceso de interiorización de antivalores que ejercen ciertas instituciones, como la propia Iglesia católica ${ }^{27}$ (jerarquía), la familia conservadora, y otras instituciones educativas de corte conservador.

Resultados de la Primera Encuesta Nacional sobre Discriminación en México, indican que 48.8\% no estaría dispuesto a permitir que en su casa vivieran homosexuales. Los discapacitados y los homosexuales son los dos grupos que, en 2005, fueron sujetos de mayor discriminación. ${ }^{28}$ Los resultados de la encuesta 2012 no varían significativamente.

Párrafo aparte merece el asunto de las madres solteras, que, también por razones de interiorización de antivalores en la sociedad, son víctimas de discriminación. Muchas de ellas son estigmatizadas por no contar con los "valores" que debiera tener toda mujer con hijos: si los ha de tener, éstos deben haber nacido dentro del matrimonio, según la perspectiva de las sociedades conservadoras, sin indagar acerca de las razones que tuvieron estas mujeres

\footnotetext{
${ }^{23}$ Ibidem.

${ }^{24}$ Consejo Nacional para Prevenir la Discriminación y la Secretaría de Desarrollo Social, Encuesta Nacional sobre Discriminación en México, 2012.

${ }^{25}$ Nueve de cada diez homosexuales opina que existe discriminación por su condición. Ibid.

${ }^{26}$ La homofobia es el miedo o rechazo hacia la homosexualidad. Es un fenómeno cultural que no es universal, ni toma las mismas formas ni tienen el mismo significado en todas partes.

${ }^{27}$ La Iglesia católica es una de las instituciones abiertamente homofóbicas. Recordemos que una de las políticas del papa Benedicto XVI es que en los seminarios se prohíba la entrada a homosexuales con el objetivo de disminuir la pederastia clerical. El significado de esto es profundo y, a la vez, equivocado: múltiples jerarcas de la Iglesia equiparan la homosexualidad con la pederastia, cuando esto es una relación absolutamente espuria. El problema sistemático en torno a la pederastia se deriva, más bien y, esto también lo formulo como hipótesis, de los desequilibrios emocionales y sexuales de algunos sacerdotes católicos, producto del celibato y del voto de castidad y no de la orientación homosexual de algunos de los integrantes de la estructura de la Iglesia católica. Cabe indicar que esta institución religiosa se encuentra aún sumida en cierto grado de desprestigio, a raíz de las demandas masivas que cientos de víctimas de sacerdotes pederastas han presentado en contra de esta institución, no sólo en México, sino en distintos países del orbe. Durante la primera quincena de marzo de 2013, los cardenales electores del nuevo papa se encontraron en conflicto pues existió un sector de ellos (los brasileños, principalmente) quienes pretendieron que se aclararan todos los asuntos relacionados con los escándalos de pederastia y los de las acusaciones de lavado de dinero por parte del Banco del Vaticano antes de entrar al cónclave y elegir al nuevo "sucesor de san Pedro". Ya veremos si el argentino Jorge Mario Bergoglio, el papa Francisco I, puede, de alguna manera, resolver los graves problemas en los que hoy se encuentra sumida la jerarquía de la Iglesia católica.

${ }^{28}$ Consejo Nacional para Prevenir la Discriminación y la Secretaría de Desarrollo Social, Primera Encuesta Nacional sobre Discriminación en México, op. cit.
} 
para concebir sin tener el estatus de casadas. Si bien es cierto que la sociedad mexicana presenta cierto grado de secularización, también lo es que éste no es suficiente para erradicar dichos antivalores y, por ende, la discriminación.

La vulnerabilidad de las madres solteras, adolescentes y jóvenes merma sus posibilidades de desarrollo tanto humano como ciudadano. No obstante, el problema es un tanto mayor dentro de este sector: la discriminación comienza por ser mujer. En este sentido, uno de cada cuatro empleadores en México pediría un examen de embarazo. Por otra parte, prácticamente uno de cada cuatro mexicanos de ambos géneros está de acuerdo con que muchas mujeres son violadas porque provocan a los hombres. En esta tesitura, tendría que existir una sociedad lo suficientemente educada y con la interiorización de otros valores para que una persona pudiese tener la libertad de vestirse como desee sin el temor a ser agredida.

Además, para casi $40 \%$ de los mexicanos, las mujeres que quieren trabajar deben hacerlo en tareas propias de su sexo. ${ }^{29}$ Tenemos un ejemplo de esto en las alumnas del Instituto Polítécnico Nacional (IPN), cuya matrícula comienza a superar la de los hombres y, según un reportaje de La fornada en marzo de 2013, dichas alumnas han tenido que tolerar manifestaciones de discriminación por parte de algunos profesores. ${ }^{30}$

\section{EFECTOS ECONÓMICOS, POLÍtTICOS Y SOCIALES}

He descrito hasta ahora el abanico de atributos que posee el sector juvenil objeto de estudio; ahora pasaré a la exposición, más explícita, de los principales efectos sociales, políticos y económicos que conlleva estar dentro de este subconjunto.

\subsection{Migración}

Desde 1982, México ha estado en una crisis económica permanente, y no ha sufrido un verdadero colapso porque, entre otras razones, la expulsión histórica de fuerza de trabajo a Estados Unidos le ha servido como válvula de escape y le ha permitido mantenerse a flote; sin embargo, la actual crisis económica estadounidense ha frenado el fenómeno migratorio, aunado y combinado con la llamada "guerra contra el narcotráfico" emprendida por el entonces titular del Ejecutivo, Felipe Calderón, que contribuyó (y sigue contribuyendo) a frenar en mayor medida los flujos migratorios. ${ }^{31}$

\footnotetext{
${ }^{29} \mathrm{Ibidem}$. Cabe indicar también aquí que los resultados emanados de la Encuesta 2012, no varían significativamente sobre este asunto.

30 "En el IPN son mujeres 6 de cada 10 inscritos", La fornada, febrero de 2013.

${ }^{31}$ Dentro del clima de violencia desatada por la guerra contra el narcotráfico, se han registrado, desde sus inicios, asesinatos en contra de migrantes so pretexto de haberlos confundido con narcotraficantes, o bien, secuestros a migrantes, tanto mexicanos como centroamericanos, que sólo buscan un mejor
} 
En 2000, fueron 400000 mexicanos los que cruzaron la frontera; para 2006 fueron 600 000. Entre estos nuevos migrantes, planteó Zatarain, ${ }^{32}$ encontramos a muchos hombres y mujeres del medio rural y urbano que tuvieron acceso a la enseñanza media superior e incluso con una profesión, pues la única alternativa para un importante sector de jóvenes, con carrera universitaria o no, se encuentra más allá de la frontera norte.

Los más de 20 millones de mexicanos, entre ellos una gran proporción de jóvenes, que han migrado a los Estados Unidos han tenido que enfrentar y resolver la circunstancia política en la que ahora viven, circunstancia que desde los atentados del 11 de septiembre de 2001 ha ido empeorando, pues la sociedad estadounidense se ha obstinado en confundir a quien migra, para trabajar en sus campos y factorías, con los terroristas islámicos. Hoy en día, con la puesta en marcha de la denominada "guerra contra el narcotráfico", los flujos migratorios han disminuido en gran medida, aunado a que muchos mexicanos emigrantes que lograron pasar la frontera tienen y tendrán un motivo más de estigmatización: el de narcotraficante.

\subsection{Violencia juvenil}

El problema de México es el número de personas jóvenes que se encuentran en estado de marginación social y económica en muchas de las entidades federativas de la nación. La bomba de tiempo que se temía ya ha estallado en el contexto de la "guerra" desatada en 2006: muchos jóvenes y niños se han enrolado en las filas del crimen organizado. Ya han sido miles abatidos en la barbarie desatada en el sexenio pasado y continuada hasta nuestros días aunque silenciada, en buena medida, por los medios de comunicación masiva.

Son dignos de mención los hallazgos presentados en el artículo: Violencia, jóvenes y vulnerabilidad en la frontera noreste de México. ${ }^{33}$ Las autoras reflexionan acerca de la irrupción de una violencia tan profunda como compleja de la cual son víctimas los jóvenes de diferentes comunidades de la ciudad fronteriza de Matamoros, Tamaulipas.

En el documento los sujetos de estudio narran formas tan perversas e inimaginables de violencia que no se acercarían a lo que pudiese escribir el director mas experto de películas de terror. Además, coloca en el centro de la mesa la reflexión de los diferentes científicos sociales, que tienen que reaprender a hacer investigación para abordar, necesariamente, el objeto de estudio de la violencia y sus múltiples aristas.

nivel de vida en los Estados Unidos. Por ello, el sacerdote mexicano Alejandro Solalinde advirtió que emprenderá una huelga de hambre si no cesan los secuestros. La fornada, marzo de 2013.

${ }^{32}$ La fornada, 2007.

${ }^{33}$ De la O, María Eugenia y Flores Ávila, Alma Leticia, "Violencia, jóvenes y vulnerabilidad en la frontera noreste de México”, en Desacatos, núm. 38, México, 2012. 
No obstante, y a manera de complemento, la violencia en México no sólo se encuentra y sigue presente en esa ciudad fronteriza, sino en casi toda la franja norte de nuestro país, así como entidades como Jalisco, Michoacán, Morelos y Veracruz y, en diversos grados, en casi todas las entidades federativas del país.

La violencia vulnera la ciudadanía de los jóvenes y disminuye en gran medida los de por sí bajos niveles de democracia en México. A los jóvenes mexicanos desempleados les quedan pocas opciones; una de ellas es la de unirse, además de los grupos de narcotraficantes y de crimen organizado, a grupos como los maras ${ }^{34} \mathrm{u}$ otros como ciertos grupos delictivos que se dedican a causar desmanes, principalmente en zonas urbanas con poca vigilancia. Una juventud violenta es uno de los problemas más difíciles para una sociedad que intenta ser democrática.

\subsection{Abstencionismo electoral}

Por su naturaleza compleja y cambiante, el abstencionismo es uno de los fenómenos políticos más difíciles de analizar e interpretar. Debido a la profundización de las crisis económicas, un sector de la población mexicana, ante la desesperanza y la desesperación tanto social como económica, ha optado por otras vías distintas a la electoral para tratar de transformar la realidad.

Un sin fin de investigaciones puedo contar sobre el abstencionismo en las cuales se toman, principalmente, sus factores socioeconómicos; entre ellos se encuentra el de Juan Campos Vega, ${ }^{35}$ quien establece que, partiendo de la base de que las causas que generaron el abstencionismo en épocas pasadas continúan presentes en la sociedad, y en todas las sociedades que tienen como base de su vida político-electoral la democracia burguesa representativa, se habrá de aceptar que el abstencionismo es un elemento consustancial de dicho sistema político, característico de la sociedad burguesa, porque el capitalismo, que constituye la base económica del sistema, se distingue por las desigualdades que genera; estas desigualdades constituyen, a su vez, la base política, económica y social del abstencionismo.

En el caso de México, lo que habría que buscar, dice Campos Vega, son los elementos nuevos que, sumados a las causas preexistentes, incrementaron el abstencionismo en las elecciones federales intermedias del 2003 y lo llevaron cerca de 60\%, muy superior al de los procesos electorales federales inmediatos anteriores. El fenómeno se torna más preocupante por la cantidad de jóvenes que se abstuvieron de votar.

\footnotetext{
${ }^{34}$ Grupo de jóvenes centroamericanos que se han distinguido por sus actos de vandalismo, extorsión y asesinatos; dicho grupo ya ha permeado territorio mexicano.

${ }^{35}$ Campos Vega, Juan, Abstencionismo y democracia, México, Partido Popular Socialista de México, 2003.
} 
Adicionalmente, el abstencionismo ha tenido una tendencia ascendente, en términos relativos, hasta las elecciones presidenciales de 2012, un tanto matizado por la presencia de los votos de los anulistas (abstencionismo cívico), principalmente en las legislativas de 2009 y, posteriormente, en 2012.

Es innegable que, en la actualidad, no solamente enfrentamos las causas tradicionales (y estructurales) que en el país generaron el abstencionismo electoral. Ahora hay nuevos elementos que analizar; entre ellos, precisamente, el detrimento o estancamiento del bienestar social y económico, así como la baja credibilidad de los jóvenes hacia las instituciones electorales, que, a su vez, señalan que el incremento del abstencionismo refleja una profunda crisis del actual sistema electoral y de partidos.

Son varios los estudios ${ }^{36}$ que demuestran que un gran sector de los abstencionistas se encuentra en desventaja social, tanto por falta de medios materiales como de oportunidades. Una gran parte del abstencionismo es consecuencia lógica del fuerte sentido de desarraigo, cuando no de subordinación, provocada por la exclusión social. Basta ver en México los niveles de exclusión y desigualdad social; esta situación socava las bases mismas del sistema.

\section{CONCLUSIONES}

El propósito fundamental del artículo fue describir, analizar y aproximarse a algunos de los factores explicativos de las diferentes problemáticas económicas, políticas y sociales que los jóvenes de los sectores más vulnerables de la sociedad mexicana enfrentan para ejercer correctamente su ciudadanía.

El sector juvenil objeto de estudio fue conformado por los mexicanos de entre 18 y 29 años con escolaridad e ingresos bajos y paternidad o maternidad tempranas. Dicha intersección conforma el sector de los jóvenes de mayor vulnerabilidad social. Además, vimos el caso en que este sector se torna más vulnerable si se agregaran la orientación sexual, el origen étnico y el estado civil. Ello se explica, en alguna medida, por la profunda discriminación que aún impera en México.

Todos estos atributos condicionan en gran medida el ejercicio de una ciudadanía plena: los derechos civiles, políticos y sociales se tornan mucho más difíciles de ejercer. Los primeros, integrados por las capacidades de ejercicio de las libertades individuales fundamentales relativas a la vida y al desarrollo integral de las personas, de expresión y pensamiento, y a las más tangibles de propiedad, contractuales y de sometimiento a los tribunales de justicia; los segundos, por un factor político compuesto por los recursos

\footnotetext{
${ }^{36}$ Jiménez Morales, Óscar Antonio, La desilusión sexenal. Abstencionismo electoral y detrimento/ estancamiento del bienestar social y económico, FRA de la Zona Metropolitana de Guadalajara, elecciones federales de 2003 y 2006. Málaga, España, Universidad de Málaga, 2012. Véase también: Jiménez Morales, Óscar Antonio, Abstencionismo electoral y deterioro socioeconómico, tomo 1, Madrid, España, EAE, 2013.
} 
de participación democrática que competen a las franquicias de elección y mecanismos de representación en la legitimación de la autoridad y el poder político; los terceros, por un factor social garantizador de las aspiraciones a una vida digna y al bienestar económico y social de los individuos, con acceso al trabajo remunerado y a la previsión social en situaciones de riesgo.

Todas estas virtudes, dentro de un marco ideal o del deber ser, se ven fuertemente vulneradas por las características del sector juvenil al que me he referido. En México, por otro lado, la democracia es deficiente en sus múltiples aristas.

En la tercera parte del artículo, se analizaron los diversos efectos económicos, políticos y sociales que conllevan estas características de vulnerabilidad. Se observó que muchos de estos efectos se traducen en migración a los Estados Unidos, en busca de lo que nunca, o pocas veces, encontraron en México. Dichos efectos se traducen también en violencia juvenil; ésta ha escaldo muchos niveles desde que Felipe Calderón emprendió la "guerra contra el narcotráfico", en la cual han sido miles los caídos, desaparecidos y las personas obligadas a migrar.

Existen en el país niños sicarios y jóvenes que participan en las filas del crimen organizado por la falta de oportunidades laborales, económicas y sociales. La baja participación política es otro de los efectos mencionados, sumada al crecimiento constante del abstencionismo electoral tanto en comicios federales como locales en las últimas dos décadas, en términos generales y dentro del sector de los jóvenes. Muchos electores, y más los que se encuentran dentro del objeto de estudio planteado, no ven en el voto una posibilidad de cambio real en sus condiciones económicas y sociales, principalmente, ni un cambio real de la política gestada en el ámbito nacional.

Problema aparte es el del alcoholismo y la drogadicción, que se observa principalmente dentro del sector en cuestión y que mina aún más el camino al ejercicio de su ciudadanía. Muchos de estos jóvenes encuentran una salida, por lo demás falsa, a sus múltiples problemáticas económicas y sociales en el abuso del alcohol y demás drogas, y son presa fácil de la gente que se dedica a la extorsión, la delincuencia y el narcomenudeo.

Un factor de vulnerabilidad que no fue abordado en este artículo y que sería material de publicación en un futuro, es el asunto de los jóvenes con capacidades diferentes, el cual contribuye a ensanchar aún más las dificultades para un correcto ejercicio de su ciudadanía.

¿Cuántas escuelas, edificios y espacios públicos carecen de infraestructura para los discapacitados? ¿Cuántos sufren discriminación, estigmatización o indiferencia por parte de la sociedad mexicana? Y qué decir acerca de aquellas niñas y jóvenes víctimas del lenocinio, quienes son obligadas a prostituirse en condiciones indignas y miserables en las calles y centros de diversión nocturna 
en muchas de las ciudades de México, provenientes de localidades y estados lejanos, víctimas del engaño o explotación, incluso de sus propios parientes. Cabe decir que muchas de ellas son amenazadas de muerte para que no salgan de las redes de prostitución donde se encuentran esclavizadas.

Todas estas problemáticas minan, vulneran y destruyen el espíritu y principalmente la capacidad natural e inherente de los jóvenes para inventar más que para juzgar, para ejecutar más que para asesorar, para emprender proyectos más que para sostener los existentes; para disfrutar de una vida más o menos plena y no hacerse responsables ya de un hogar o una nueva familia; para vivir en un clima de paz, solidaridad y tranquilidad; para vivir, para soñar, para disfrutar.

Son los jóvenes quienes tienen la responsabilidad de transformar y revolucionar el país y contribuir a destruir el México antidemocrático, corrupto, desesperanzador y violento. 